\title{
The relationship between climate and outbreak characteristics of the spruce budworm in eastern Canada
}

\section{David R. Gray}

CC Springer Science + Business Media B.V. 2008

\section{Erratum to: Climatic Change (2008) 87:361-383 DOI 10.1007/s10584-007-9317-5}

Unfortunately, in the printed version of this article Figs. 1, 2, 5 and 6 were displayed in black and white where colour reproduction was necessary. Please find the colour figures below.

Fig. 1 The 4,744 cells (30,000 ha) in which forest composition, climate variables, and spruce budworm outbreak characteristics were summarized



The online version of the original article can be found at http://dx.doi.org/10.1007/s10584-007-9317-5.

D. R. Gray $(\varangle)$

Natural Resources Canada, Canadian Forest Service - Atlantic Forestry Centre,

P.O. Box 4000, Fredericton, NB E3B 5P7, Canada

e-mail: dgray@nrcan.gc.ca 

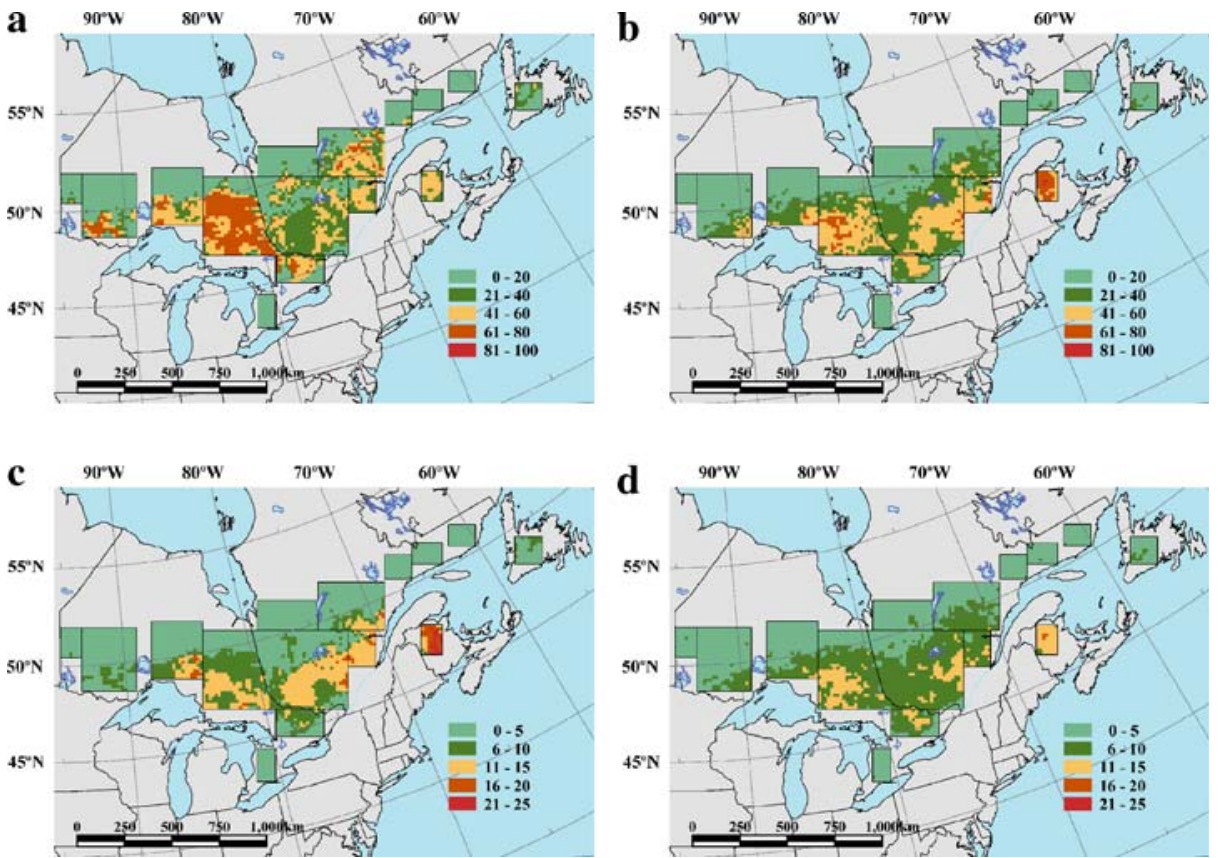

Fig. 2 Historical observations, and model predictions, of outbreak severity (\% defoliation) and duration (years) in the 3,245 cells used to build the model. Cells within each rectangular grid were permuted in Monte Carlo simulations for significance testing of explanatory variables. a observed severity; b predicted severity; c observed duration; d predicted duration

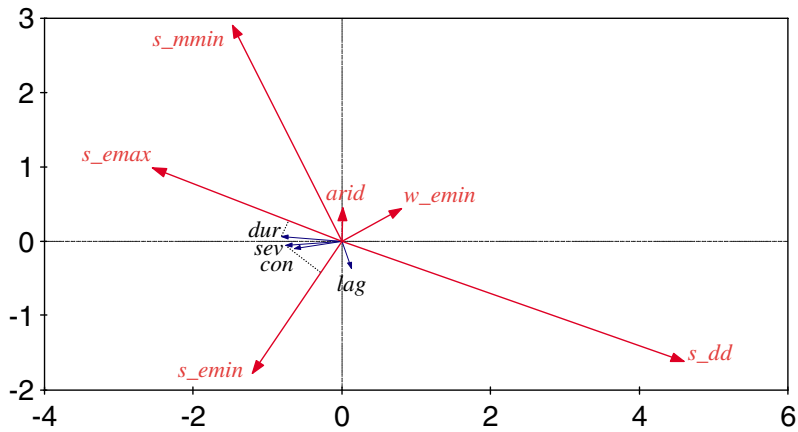

Fig. 5 Regression biplot of the model where $\mathbf{Y}$ is the matrix of spruce budworm outbreak characteristics, and $\mathbf{X}$ is the combined matrix of significant climate variables, forest composition, and geographic location. For clarity, only the climate variables $\left(\mathbf{X}_{\mathrm{C}}\right)$ have been displayed. A regression biplot shows the rate of change in $y_{k}$ (a variable of $\mathbf{Y}$ ) per unit change in $x_{j}$ (a variable of $\mathbf{X}$ ) when the other variables of $\mathbf{X}$ are held constant. The change in $s \_$emax or $s \_$emin (proportion of 1 s.d.) necessary to produce a-1.0 s.d. change in $d u r$ and $s e v$, respectively, are shown by the dotted lines that intersect the $s \_$emax and $s \_$emin vectors 

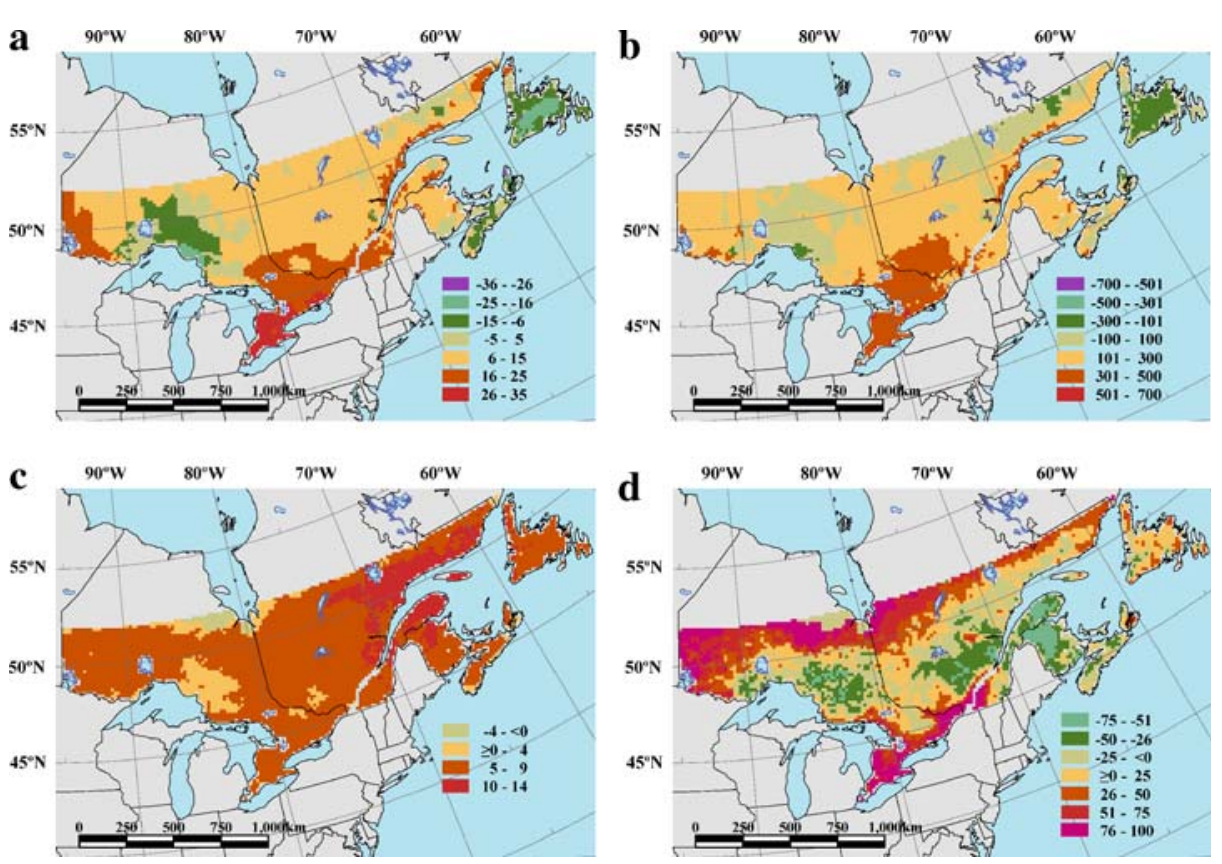

Fig. 6 Projected changes (2081-2100 values minus historic values) in climate variables $s_{-}$emax $\left({ }^{\circ} \mathrm{C}\right)$ and $s \_d d\left({ }^{\circ} \mathrm{C}\right.$-day), and the predicted changes to spruce budworm outbreak duration (years) and severity (\% defoliation; future model predictions minus historic model predictions). a predicted change in $s \_$emax; b predicted change in $s \_d d$; $\mathbf{c}$ predicted change in duration; d predicted change in severity 